Article

\title{
Forest Cover Database Updates Using Multi-Seasonal RapidEye Data-Storm Event Assessment in the Bavarian Forest National Park
}

\author{
Alata Elatawneh ${ }^{1}{ }^{1 *}$, Adelheid Wallner ${ }^{1}$, Ioannis Manakos ${ }^{2}$, Thomas Schneider ${ }^{1}$ and \\ Thomas Knoke ${ }^{1}$
}

1 Institute of Forest Management, Center of Life and Food Sciences Weihenstephan, Technische Universität München, Hans-Carl-von-Carlowitz-Platz 2, Freising 85354, Germany; E-Mails: adelheid.wallner@tum.de (A.W.); tomi.schneider@tum.de (T.S.); knoke@forst.wzw.tum.de (T.K.)

2 Information Technologies Institute, Centre for Research and Technology Hellas, Building A, 6th km Harilaou-Thermi, P.O. Box 60361, Thessaloniki 57001, Greece; E-Mail: imanakos@iti.gr

* Author to whom correspondence should be addressed; E-Mail: alataaa@tum.de; Tel.: +49-8161-71-4272; Fax: +49-71-8161-4545.

Received: 26 February 2014; in revised form: 19 May 2014 / Accepted: 29 May 2014 / Published: 11 June 2014

\begin{abstract}
This study is a part of a research program that investigates the potential of RapidEye (RE) satellite data for timely updates of forest cover databases to reflect both regular management activities and sudden changes due to bark beetle and storms. Applied here in the Bavarian Forest National Park (BFNP) in southeastern Germany, this approach detected even small changes between two data takes, thus, facilitating documentation of regular management activities. In the case of a sudden event, forest cover databases also serve as a baseline for damage assessment. A storm event, which occurred on 13 July, 2011, provided the opportunity to assess the effectiveness of multi-seasonal RE data for rapid damage assessment. Images of sufficient quality $(<20 \%$ cloud cover) acquired one day before the storm event were used as a baseline. Persistent cloud cover meant that the first "after event" image of sufficient quality was acquired six weeks later, on 22 August, 2011. Aerial images (AI) for the official damage assessment done by the BFNP administration were acquired on that same day. The RE analysis for damage assessment was completed two weeks after the post-event data take with an overall accuracy of $96 \%$ and a kappa coefficient of 0.86 . In contrast, the official aerial image survey from the BFNP
\end{abstract}


was first released in late November, eleven weeks later. Comparison of the results from the two analyses showed a difference in the detected amount of forest cover loss of only $3 \%$. The estimated cost of the RE approach was four times less than that of the standard digital AI procedure employed by the BFNP.

Keywords: forest cover monitoring; multi-seasonal; RapidEye; aerial images; storm damage

\section{Introduction}

In Central Europe, the most important natural disturbances in forests are storm events [1,2]. Disastrous events of, at least, "regional" dimensions have the potential to destabilize the timber market and trigger subsequent biotic calamities. Such event sequences occurred in 1991 and 1999 following the storms "Vivian/Wiebke" and "Lothar" in Southern and Southwestern Germany respectively. The most common biotic calamity following such a storm event is an extreme increase in propagation of the European spruce bark beetle (Ips typographus [L.]) [2-5]. Forest area depletion must be recorded and spatially located in order to delineate drivers, pressures, threats and impacts, and to issue warning signals and take mitigation actions wherever appropriate [6]. However, this requires baseline data on forest cover, generally acquired from forest management databases. Currently, forest management databases are available only for the state forests in Germany and for some community forests (less than $40 \%$ of the forests in Bavaria). The update cycles for these databases can be as long as 10 years. Increasing frequency and magnitude of disastrous events during recent decades has revealed the need for shorter update cycles for such databases. At present, in Bavaria, about 30 to $40 \%$ of the annual workload of a forest enterprise is in response to unpredictable hazardous events [7]. In order to prevent follow-on calamities like those described above, it is important to immediately clear affected areas, which in turn requires reliable information about the site, its accessibility, existing nearby facilities, availability of resources, and administration constraints on management of the affected area, such as restrictions which are meant to protect sites of cultural and natural importance.

To tackle some of these challenges, a Decision Support System (DSS) (Entscheidungs-UnterstützungsSystem Forst-Holz, EUS-FH) project was designed for the forest-wood chain in Bavaria, which at the same time enables the fulfillment of both national and international reporting duties. EUS-FH contains a database-updating module that is based on remote sensing (RS) data [7]. This module, known as the "Remote Sensing-based Inventory and Monitoring System" (RS-IMS), is based on the idea of integrating existing data from official sources, such as the Bavarian Surveying and Geoinformation Administration (LVG), the Bavarian State Forest Administration, the Bavarian State Research Institute of Forestry, community forests, and National Parks like the Bavarian Forest National Park (BFNP) with RS data in order to update existing knowledge and to support trend analysis. The development of the EUS-FH was prompted by the launch of the German satellite systems TerraSAR-X (TS-X) and RapidEye (RE). The spatial resolutions of both systems fulfill the requirements of a 1:10,000 mapping scale [8], while the high acquisition frequency of two to three days [9] allows for operational and near real-time application of the data acquired. 
Within the RS-IMS, special attention is given to detecting sudden canopy losses due to either natural or human-induced events. Using active sensors, changes due to both regular management and sudden events can be assessed within a short time, even under the cloud regime common in central Europe, where images with less than $20 \%$ cloud cover are rarely acquired. Recent studies, such as those by Rappl et al. [10], and Thiele et al. [11], have utilized data from the active sensor, TerraSAR-X, for the same area referenced in this study to assess the potential of these data for rapid mapping of windstorm events. However, these studies were more experimental than operational due to the small area coverage and high cost of the TerraSAR-X data.

A windstorm, which occurred between late night 13 July, 2011, and early morning 14 July, 2011, in the northern part of the BFNP, was the trigger for this study. A few months later, about $70,000 \mathrm{~m}^{3}$ of timber was thrown down by the storm [12]. Thus, the conditions for a "regional" event were fulfilled. The processing chain within the 'Remote Sensing based Inventory and Monitoring System' (e.g., EUS-FH) is based on object-based change detection (OBCD) techniques, which have demonstrated advantages over pixel-based change detection techniques [13]. Chen et al. [14] classified OBCD methods into four groups: image-object, class-object, multitemporal-object, and hybrid change detection. The advantages and disadvantages of implementing these methods have been discussed in previous studies [15-17] in which hybrid methods performed better than others for forest change detection. OBCD has been used in several forest studies undertaken in the last decade to describe forest dynamics due to both biotic and abiotic disturbances. These studies have used Landsat [17-20] and SPOT images [15,16], as well as data from very high spatial resolution sensors, such as QuickBird and aerial images (AI) [4,21]. The topics addressed in these studies were as diverse as forest loss and disturbance monitoring, the potential and limitations of the techniques used, and the contribution of the results to further ecological analysis. However, while these studies utilized multi-annual images to perform annual updates of the forest status, they did not make use of multi-seasonal data, as was done in the study presented here. In addition, the problem of cloud presence was either avoided completely by working with cloud-free data [16], or the use of either more frequent optical data or data from active sensors to enhance the results where clouds exist was recommended [17]. In contrast, multiseasonal RE data (acquired every 45 days) are now available for the whole of Germany, according to the agreement between the German Federal Ministry of Economics and Technology (BMWi) and the RapidEye data provider.

In the study presented here, an innovative hybrid change detection technique was applied to multi-seasonal RE images to update an existing forest cover database. A new approach was developed to overcome the problem of partial cloud cover by using substitute data from subsequent data takes. This method was implemented on data from two different periods.

- The first period, between 19 April, 2011, and 22 June/12 July, 2011, helped to update the forest cover figures obtained from the most recent forest inventory for the area, which was done in order to document changes due to regular management practices.

- The second period, between 22 June/12 July, 2011 and 22 August, 2011, was after the above-mentioned storm event had occurred. This helped to demonstrate the evaluation chain for sudden catastrophic events by applying the same method.

The results of both periods were then compared to the results of the annual official AI survey from 2011, which was obtained from the BFNP. Finally, the costs of using each of the data sources and 
associated methods were estimated and compared in order to assess their relative potential for operational use.

\section{Experimental Section}

\subsection{Study Area}

The study site is located in the northern part of the BFNP in southeastern Germany (49 $03^{\prime} 53^{\prime \prime} \mathrm{N}$, $13^{\circ} 21^{\prime} 57^{\prime \prime}$ E) along the border with the Czech Republic (Figure 1). Together, the BFNP and the Sumava National Park in the southwestern part of the Czech Republic cover an area of $940 \mathrm{~km}^{2}$ and form the most extensive protected forest in Central Europe. The BFNP is located in a mountainous region, with elevations ranging between $600 \mathrm{~m}$ and $1450 \mathrm{~m}$. The BFNP was founded in 1970 as Germany's first national park with an area of $130 \mathrm{~km}^{2}$. In 1997, the park was extended to include a total area of $240 \mathrm{~km}^{2}$. Its landscape can be divided into three ecological zones-highlands, hillsides, and valleys. In each zone, different compositions of tree species are located. Based on inventory results from 2002 to 2003, Heurich and Neufanger [22] calculated the following tree species compositions for the dominant layer of the forest in each of these ecological zones: (a) In the highlands $-90 \%$ Norway spruce (Picea abies), 2\% beech (Fagus sylvatica), and 8\% other broadleaf trees; (b) on hillsides-58\% Norway spruce, $3 \%$ fir (Abies alba), 34\% beech, and 5\% other broadleaf trees; and (c) in the valleys - $83 \%$ Norway spruce, $5 \%$ fir, $6 \%$ beech, and $6 \%$ other broadleaf trees. Thus, the main species in all of the ecological zones in the study area is Norway spruce, which is highly susceptible to damage due to calamities.

Figure 1. Location of the Bavarian Forest National Park.
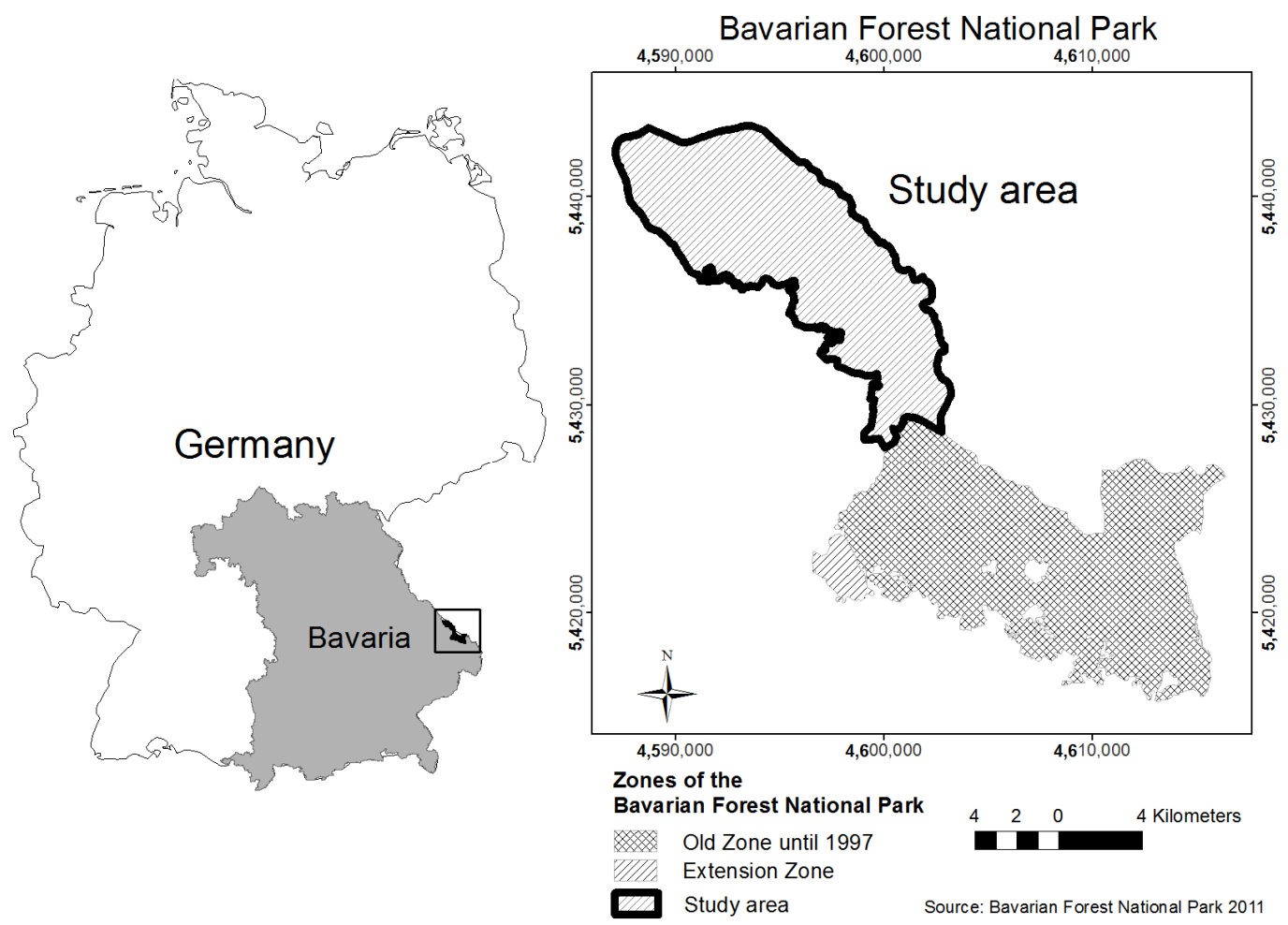
Severe disturbance cycles have been documented in the forest in the Bavarian Forest National Park (BFNP) since 1868 [23]. However, the frequency of disturbances has been increasing since 1983 and peaked at the beginning of the 1990 s when about $17,000 \mathrm{~m}^{3}$ of wood was affected [24]. As a reaction to the forest disease discussion, which began in the 1980s and was triggered by the aforementioned disturbance cycle in the BFNP, annual inventories using aerial photography have been performed since 1988 [4]. At present in the BFNP, in the case of an unpredictable event like storm break, fire, or biotic infestation, AI interpretation is always used to investigate the changes. The minimum mapping unit used in previous studies of this kind in the BFNP [4,5,25] has always been a patch of at least 5 trees. No reports have been issued describing the results of these analyses, but all changes have been documented in the annual updates. Despite the fact that automated approaches to change detection have been tested [4], visual interpretation is still considered the most reliable approach and is still officially used in the BFNP [25].

The philosophy of the BFNP administration allows no forest management activities in the core zone of the park. However, some small, private residential areas and agricultural fields still exist within the park boundaries. Bark beetle management is allowed within the park itself only in a small strip of 500-800 $\mathrm{m}$ along the boundaries of these areas and along the external boundaries of the park. A monitoring and management system has been established to observe calamity development and prevent further bark beetle breakouts in the extended zone.

\subsection{Data Sets}

\subsubsection{RapidEye Data}

RE data were the primary data used for this analysis. These data consist of five channels: one each in the blue, green, red, red edge, and near infrared regions of the spectrum. Typically, the data are collected at nadir, with a spatial resolution of $6.5 \mathrm{~m}$ ( $5 \mathrm{~m}$ resampled $)$ and a swath width of $75 \mathrm{~km}$. The data were ordered as level 3A products and provided by the RapidEye Science Archive (RESA) at the German Aerospace Center (DLR). Even at the nominal repetition time of the RE system of 2-3 days, only three scenes acquired during the period between April and October, 2011, fulfilled the maximum $20 \%$ cloud cover condition we set for this analysis; the first of these images was acquired on 19 April, 2011, the second on 22 August, and the third on 1 October. To cover the main growing season from May to July, two additional scenes, namely one from 22 June and one from 12 July, were combined to produce a dataset meeting the cloud coverage restrictions.

\subsubsection{Ancillary Data}

Reference data containing information about the losses in forest cover in the year 2011 were obtained from the BFNP administration and compared to the results of the data analysis performed here. Each year, flight campaigns are performed by the park administration to acquire color-infrared images (CIR), which are then used to update the databases of the BFNP [4]. Any changes in forest extent or condition are identified using visual image interpretation. For the analysis of changes that occurred in 2011, five change classes were defined, of which four described the effects of bark beetles, and one those of the storm. The change classes due to the bark beetle were referred to as standing 
deadwood, groups of standing deadwood (max. 5 trees), cleared area of deadwood, and area of hand-debarked deadwood [25]. All of the classes described were delineated by hand using stereoscopic image interpretation. In 2011, the flight campaign was initiated by the storm event on 13 and 14 July, 2011. The first date after this event when cloud cover was sufficiently low to allow imaging was 22 August.

\subsection{Methodology}

\subsubsection{Data Preprocessing and Preparation}

The mapping accuracy of change detection using remote sensing systems is affected by the following factors: spatial scale, sensor viewing geometry, image geometric accuracy, and radiometric normalization [14]. All of the RE images used in this study were collected with the nominal $0^{\circ}$ pointing geometry, resampled to $5 \mathrm{~m}$ pixels, and were ordered preprocessed to level $3 \mathrm{~A}$. The geometric accuracy of RE level $3 \mathrm{~A}$ data ranges from less than one pixel to six pixels $(5 \mathrm{~m}-30 \mathrm{~m})$ [9]. The geometric accuracy of the data as acquired was examined and, when necessary, improved using co-registration to the available geo-databases, using ENVI 4.3. As is essential for multi-seasonal data evaluation, a combined atmospheric/topographic correction was performed using ATCOR 3 implemented in PCI Geomatica software. Thus, the resulting data set represents actual reflectance.

\subsubsection{Detection of Forest Cover Loss}

The basic concept of the method applied is to initially obtain change results using any of the various commonly used pixel-based change detection algorithms, and then apply the object-based technique to enhance the results [26]. In this way, the calculation time can be reduced by avoiding segmentation of the whole image, while at the same time allowing for automation of the process. The processing chain that was developed to aid in the annual update of forest databases compares any new data set with a previous one by applying a pixel-based technique, and a simple image-differencing algorithm ([27] and Figure 2). This algorithm computes the differences between the two images by subtracting the pixel values from the initial state image from those of the next state image. The closer the acquisition date of the later image data to a change event, the higher the spectral contrast and, thus, the better the ability to detect resulting changes. The result of this process is a difference image for each band of data representing the changes between the two state images, in which positive values identify pixels that became brighter, and negative values identify pixels with lower reflectance values Equation (1).

$$
\left[\Delta x_{i j}^{k}=x_{i j}^{k}\left(t_{2}\right)-x_{i j}^{k}\left(t_{1}\right)\right]
$$

where $x_{i j}^{k}=$ the pixel value for band $k ; i$ and $j$ are the $x$ and $y$ coordinates of each pixel; $t_{1}=$ the acquisition date of the initial state image; $t_{2}=$ the acquisition date of the second state image.

Equation (1) was solved for each RE band, as well as for a series of indices calculated from the raw band data, such as brightness, blue/green ratio, and NDVI. Afterwards, all resulting difference images were assessed visually. This evaluation of the huge windthrow area showed very clearly that the red edge band outperformed all other bands in quantifying the extent of the wind damage [28]. The results from the other bands and indices overestimated the losses in forest cover. 
Figure 2. Overall methodology followed for the detection of loss in forest cover in the BFNP for the first period and second period.

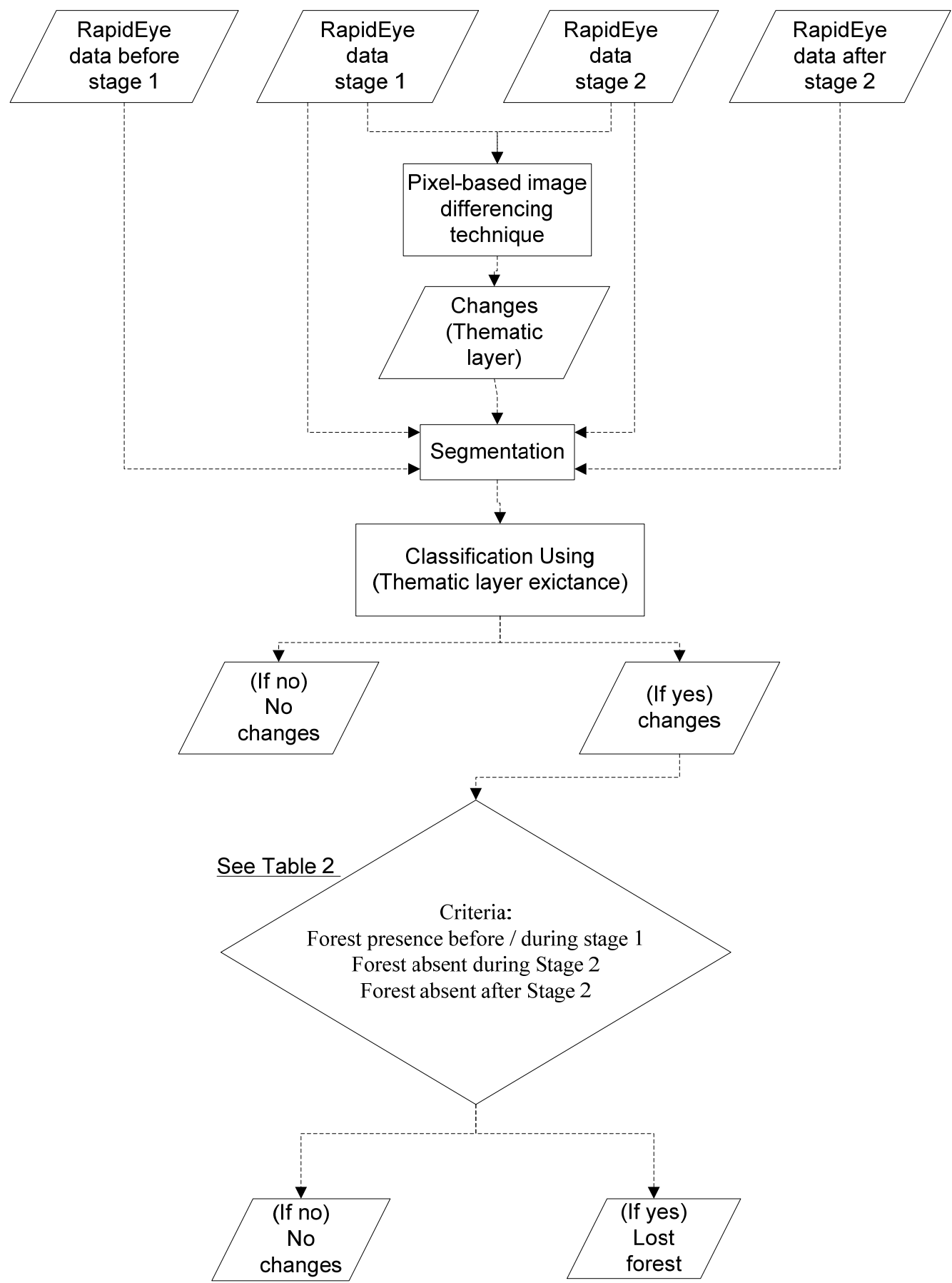

Losses in forest cover resulted in positive values, due to the increase of reflectance in all bands (except the green band) in the second stage image. Therefore, only areas with positive values were used for further analysis. This can be explained by the fact that forest has the lowest reflectance of any vegetative land cover, and, thus, any losses in forest cover will result in brighter reflectance values [29]. However, the areas with positive values in the initial result included not only areas of lost forest cover, but also areas where the changes in reflectance were due to clouds and their shadows, water bodies, and variations in phenology - especially in fields surrounding the forests. In the next step, a difference image representing all positive values was produced to be refined in the object-based environment. 
For the object-based analysis (OBIA), eCognition software from Trimble (formerly Definiens) was used. A rule set, consisting of a batch of commands, was developed in eCognition for this study. The multi-resolution segmentation algorithm, which allows for the integration of a geo-database into the segmentation process and assigns weights to all bands, was used. In the segmentation process, the difference image that represents all detected positive values was used to create objects based on its borders. This was done to ensure that the exact extraction of the pixel-based change detection resulted in the formation of objects. Additionally, a few parameters, such as scale parameter, shape, and compactness, were estimated based on a trial and error iteration procedure (see Table 1). In the second part of the process, all objects were initially classified as "change" or "no change" based on the difference image representing positive values. The results were then refined in order to detect only the areas where forest cover was lost between the two data takes. To be assigned as lost forest, an object had to meet all of the following three criteria:

(I) Existence of forest during the first stage (first data take) or before the first stage, as derived from additional RE data from previous image takes, in case of the presence of clouds during first data take.

(II) Forest absence in the second stage (second data take).

(III) Forest absence after the second stage, in case of the presence of clouds during the second data take, also derived from later RE data takes.

Table 1. Multi-resolution segmentation parameters used in eCognition.

\begin{tabular}{ccc}
\hline Parameter & First Period (April-June/July) & Second Period (June/July-August) \\
\hline Scale & 20 & 20 \\
Shape & 0.1 & 0.1 \\
Compactness & 0.9 & 0.9 \\
Bands weights & All bands from April and August, & All bands from April, August and \\
& the given weight was 1 & October, the given weight was 1 \\
\hline
\end{tabular}

The indices used to refine the results by these criteria are presented in Table 2. Criterion number one excluded all changes that occurred outside the forest area, such as changes due to water bodies or seasonal variations in plant phenology in nearby fields. Where clouds were present, criterion number one used also previous RapidEye data from before stage 1 to check the existence of the forest. Criterion number two examined whether the areas where the changes occurred were actually still forested in the second stage. If this was found to be the case, these changes were excluded from the forest change category and instead attributed to seasonal changes due to forest plant phenology. Where clouds were present in the second stage image, criterion number three safeguarded that the remaining changes did not belong to forest cover, by using subsequent RE data from after the second stage. After the application of all three criteria, objects that were still seen as changes in forest cover were assigned as lost forest. 
Table 2. The indices used to create the three criteria used to extract the forest loss areas (see Figure 2).

\begin{tabular}{ccc}
\hline Criterion & First Period (April-June/July) & Second Period (June/July-August) \\
\hline & Blue/Green ratio (April) & Blue/Green ratio (April) \\
Forest present before/during stage 1 & Brightness (April) & NDVI (April) \\
& NDVI (April) & \\
Forest absent during stage 2 & Blue/Green ratio (June/July) & Blue/Green ratio (August) \\
& NDVI (June/July) & \\
Forest absent after stage 2 & Blue/Green ratio (August) & NDVI (October) \\
\hline
\end{tabular}

\subsubsection{Accuracy Assessment and Comparison with the Aerial Images Results}

The change detection performance was assessed via an error matrix. Polygons were used as sampling units rather than points, as points tend to underestimate the accuracy of object-based results [30]. Each polygon was formed by centering a circle of $60 \mathrm{~m}$ in diameter on one corner of a $\left(350 \times 350 \mathrm{~m}^{2}\right.$ cell size $)$ grid. This diameter was based on the average size of the objects formed during the change detection process. The reference values (change/no change) for these sampling units were assigned based on visual interpretation of the three RE scenes from April to October, additionally supported by interpretation of the aerial images from August. If any change was found within a polygon, it was assigned to the change category. Then, the agreement between the change detection results and the reference value was visually assessed for each polygon. In total, 849 polygons distributed systematically over the study area were used for the accuracy assessment. Out of this process, the overall user and producer accuracies, as well as the kappa coefficient were obtained [31,32]. This accuracy assessment process was carried out for the results from both the RE and the aerial images, and the results were compared to one another.

\subsubsection{Cost Comparison between RapidEye Data and Aerial Images}

For the cost calculation, it was assumed that reference data would already be available before the occurrence of a storm event and thus, only data from after the storm event need be acquired. Three main cost categories were taken into consideration: the price of the raw data, the cost of data pre-processing and data analysis. The raw data cost was calculated based on the number of images needed to cover the study area. At least a thousand aerial images of the resolution regularly used by the annual survey are necessary to cover this study area, at a cost of $€ 18$ per image, according to LVG. While only four RE images are enough to cover the same area, an additional four images were needed in this case to overcome the problem of cloud cover. Therefore, eight RE images were acquired, at a cost of $€ 593$ each. The costs for preprocessing and data analysis were calculated based on the working hours $(\mathrm{WH})$ needed to complete them. An hourly rate of thirty-five Euros/hour ( $€ 35 / \mathrm{h})$ was assumed, based on the average gross/hour of the actual public payment scheme in 2011 for workers with appropriate skills. Preprocessing steps included: Geometric correction, triangulation and atmospheric correction (only for RE data). The data analysis consisted of visual interpretation for the aerial images, and implementation of the hybrid method for the RE data, as described in this study. 


\section{Results}

\subsection{Solving the Problem of Cloud Cover}

In order to determine the amount of forest cover lost using the multi-seasonal RapidEye data, the problem of cloud cover in the images had to be overcome. Figure 3 shows an example of how the method handled the problem of cloud presence during the second image acquisition period (from 22 June/12 July to 22 August). The results of the initial changes are presented in Figure 3 (left and middle), while Figure 3 (right) shows the final results for "lost forest" and the changes, which were excluded after refinement by application of the three criteria.

Figure 3. Example of how additional data from an additional Rapid Eye (RE) image were used to overcome the problem of the presence of clouds in two RE images used for change detection analysis. Initial analysis of the changes between an image from 22 June/12 July (left) and one from 22 August (middle) indicated differences, which were actually due to either clouds or lost forest. Additional data from the image from 1 October (right) facilitated the exclusion of those changes due to clouds and produced the final results showing the actual losses in forest cover, by implementing (1) first criterion; (2) second criterion; and (3) third criterion.



In this example, the first criterion excluded the objects that were not forest on 22 June, and the second criterion excluded the objects that were still forest on 22 August. However, few objects were actually excluded until the third criterion was implemented. The third criterion used the data collected on 1 October to exclude all objects still identified as forest. Thus, only the changes that represented an actual loss of forest cover remained.

\subsection{RapidEye Analysis and Accuracy Assessment}

The change detection result in Figure 4 shows the amount of forest cover lost during the first period from 19 April to 22 June/12 July. The polygons representing lost forest cover are shown overlaid on top of the two RapidEye images from April and June. As can be seen, the areas within the polygons appear to be darker in the April image than they do in the June image due to the loss of forest cover. 
Such a visual comparison shows that the method being tested here achieved relatively accurate mapping of the losses. Most of these losses were probably due to management against bark beetle. Based on the analysis, an area of about 157 ha of forest cover were lost during this period. The change detection result in Figure 5 shows the amount of forest cover lost during the second period (from 22 June/12 July to 22 August). Visual comparison between the images from June and August shows that the result accurately delineated the losses in forest cover, most of which were due to the catastrophic wind storm that occurred in July. Based on this analysis, an estimated area of about 235 ha of forest cover was lost during the second period.

Figure 4. Example of some of the forest cover losses during the first period of analysis from 19 April to 22 June/12 July which were detected using RapidEye data.
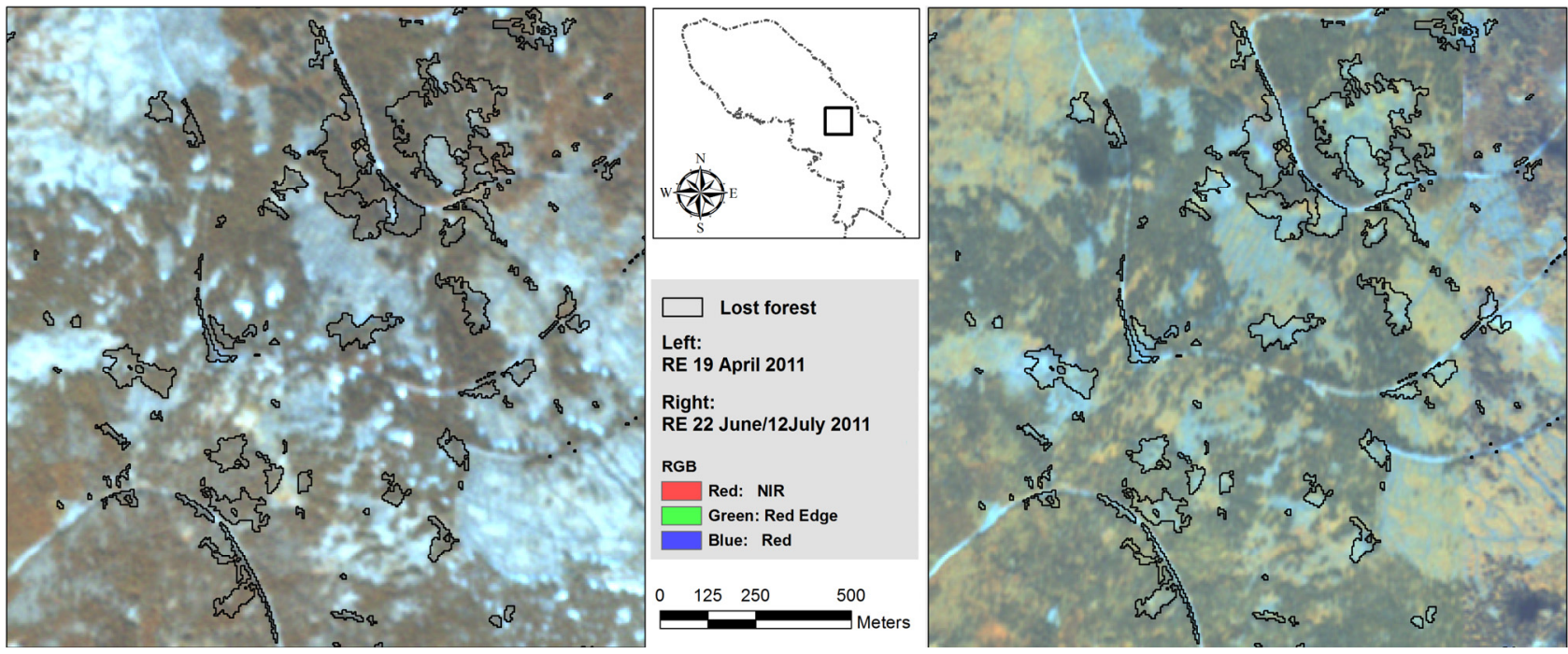

Figure 5. An example showing the forest cover losses during the second period of analysis from 22 June/12 July to 22 August detected using RapidEye data.
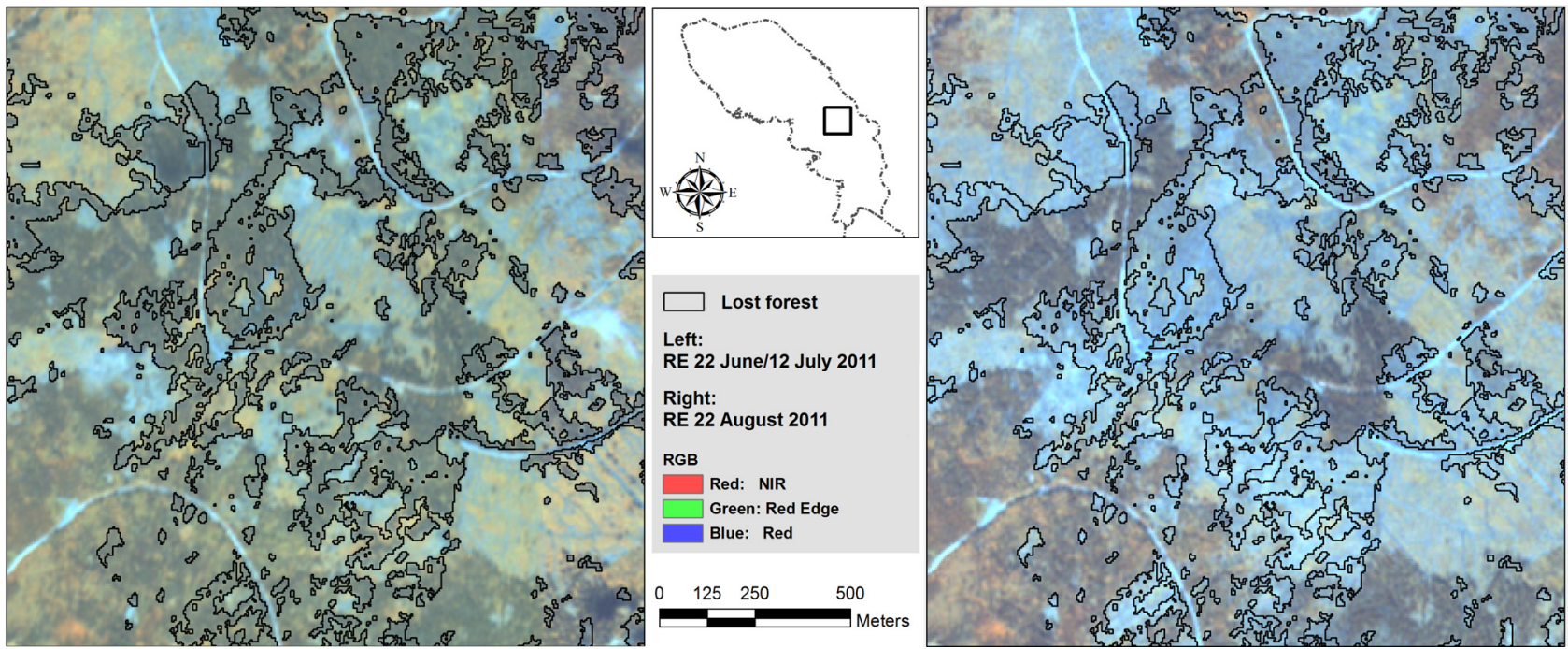

In total, an area of about 392 ha of forest cover was lost during the period from April to August (Figure 6-left). The statistics from the accuracy assessment are presented in Table 3. Overall, the change detection method used here returned satisfactory results in terms of identifying the amount of 
forest cover lost, given a 5-m spatial resolution. With reference to the error matrix (Table 3), an overall accuracy of $96.7 \%$ and a kappa of 0.86 were achieved - a result which indicates a high level of agreement with the reference data.

Table 3. Error matrix for the change detection results using RapidEye data.

\begin{tabular}{cccc}
\hline \multicolumn{3}{c}{ Reference } \\
\hline Change Detection RE & Change & No Change & User's Accuracy \% \\
change & 104 & 15 & 87.4 \\
no change & 13 & 717 & 98.2 \\
producer's accuracy \% & 88.9 & 98.0 & kappa 0.86 \\
& & & overall accuracy $96.7 \%$ \\
\hline
\end{tabular}

The user and producer accuracies for the "lost forest" class were $87.4 \%$ and $88.9 \%$ respectively, indicating the overall success of the classification. In addition, the high producer's accuracy indicates a good degree of success in identifying most of the forest cover that was lost. However, a few losses were not detected and a few objects were mistakenly identified as losses when no actual loss had occurred. These errors were checked against the high-resolution aerial images as will be discussed later.

\subsection{Accuracy Assessment of the Aerial Images}

In order to assess the success of the results of the RapidEye data analysis in comparison to the results of the aerial image interpretation, the accuracy assessment of the aerial image was accomplished using the same method. The resulting forest cover losses, derived through on-screen digitizing of the aerial images, are shown in Figure 6 (right).

Figure 6. An example showing total forest cover losses during the period from 19 April to 22 August detected using (left) analysis of RapidEye data and (right) visual interpretation of aerial images.
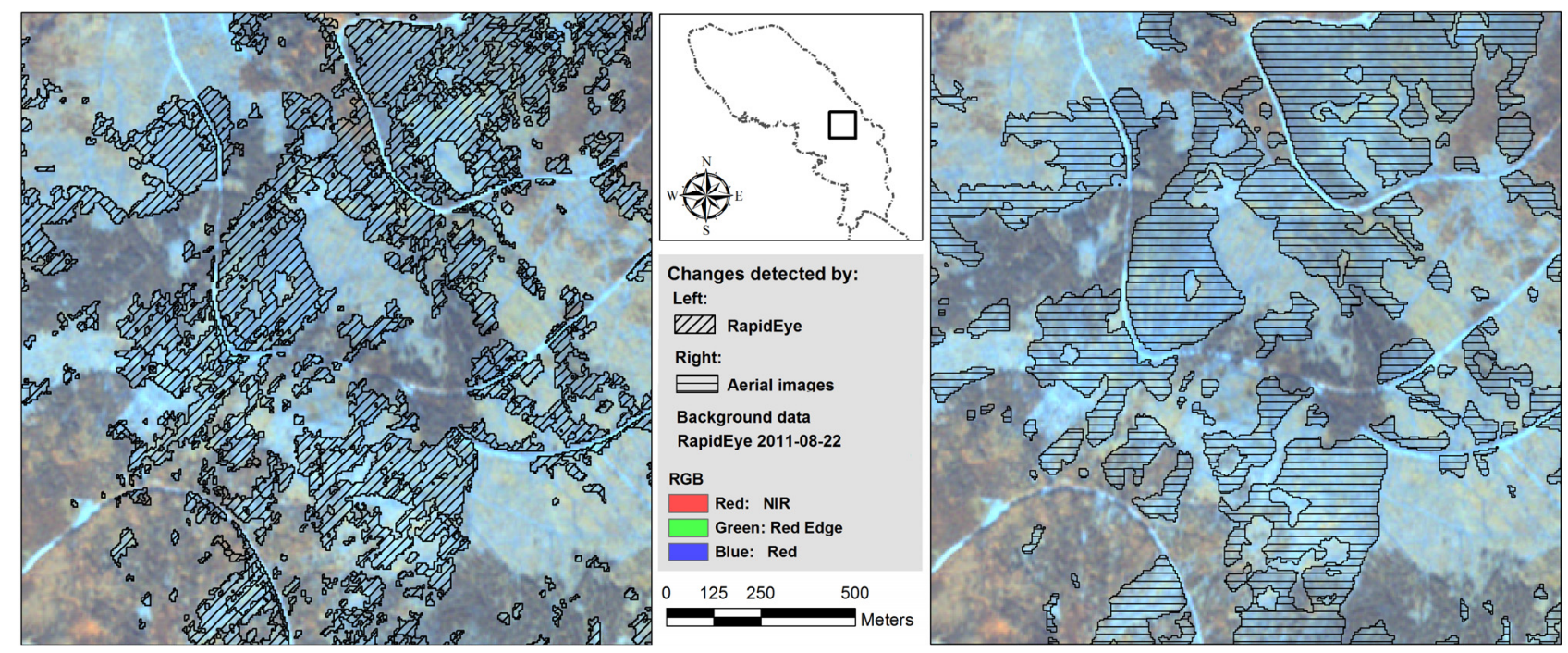

The accuracy assessment statistics are presented in Table 4. An overall accuracy of $98.1 \%$ and a kappa of 0.92 , and user and producer accuracies for the "lost forest" class of $100.0 \%$ and $86.3 \%$ 
respectively were achieved. A 100\% user's accuracy is expected from a visual interpretation of aerial images. Based on aerial image interpretation, an area of about 373 ha of forest cover loss was estimated.

Table 4. Error matrix for the change detection results using Aerial images.

\begin{tabular}{cccc}
\hline \multicolumn{3}{c}{ Reference } \\
\hline Change Detection AI & Change & No Change & User's Accuracy \% \\
change & 102 & 0 & 100.0 \\
no change & 16 & 733 & 97.9 \\
producer's accuracy \% & 86.4 & 100.0 & kappa 0.92 \\
& & & overall accuracy $98.1 \%$ \\
\hline
\end{tabular}

\subsection{Results and Cost Comparison between RapidEye and Aerial Images}

The resulting maps of forest cover losses in the study area from both RapidEye data analysis and aerial images are presented in Figure 7. Statistics showing the level of agreement in hectares between the two results are depicted in Table 5. With reference to the intersection statistics, as observed, the agreement between the two results was found to be very high, and 361 hectares of forest loss were classified identically in both.

Figure 7. Example showing the forest cover losses that were detected only when using aerial image interpretation, those which were detected only when RapidEye data was used and those which were detected using both methods.
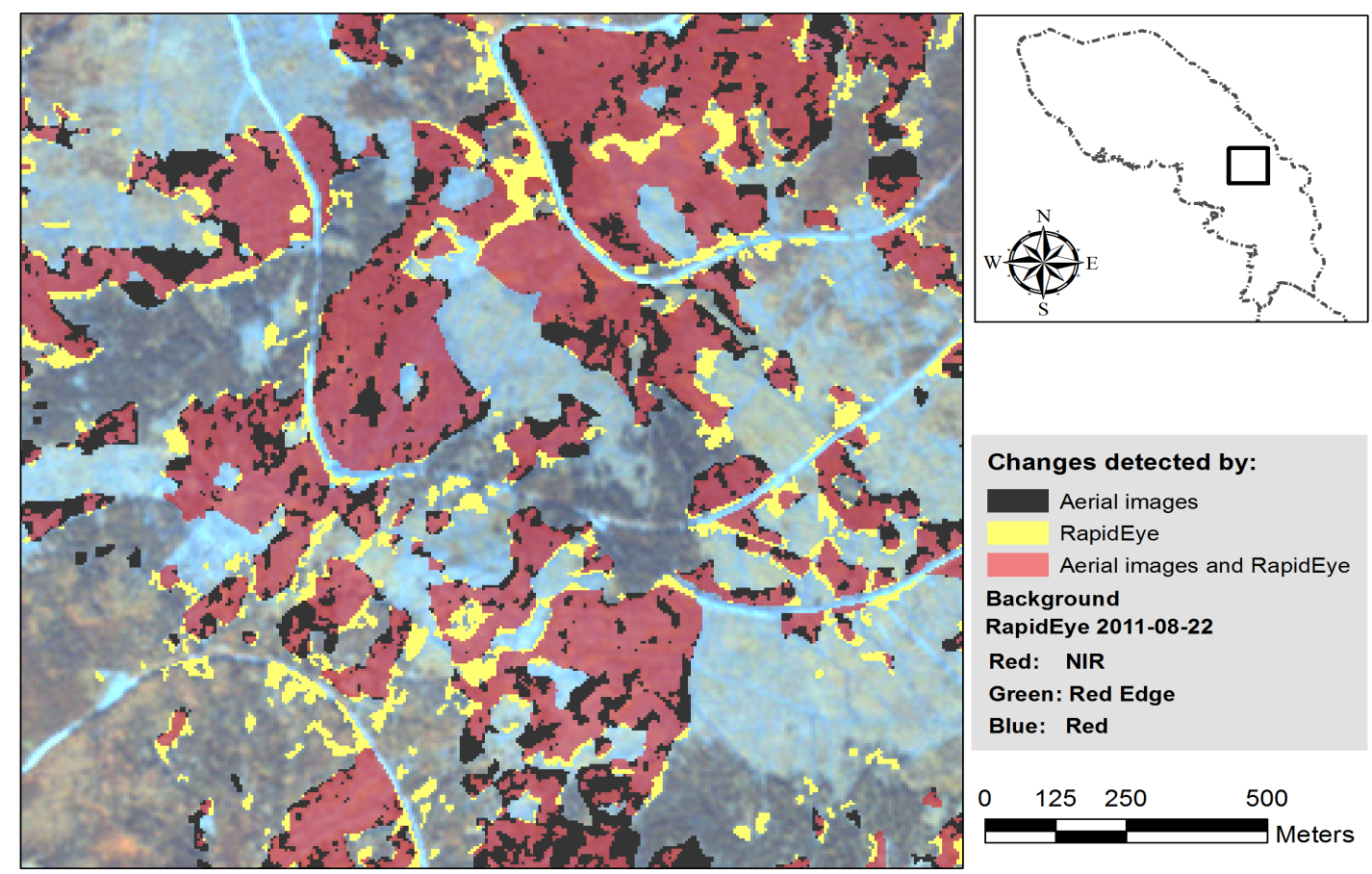

A comparison of the map produced from the analysis of the RapidEye images with the one produced using aerial image interpretation showed generally a very high similarity in the lost forest patch shape and spatial distribution. However, there were some differences between the two outcomes. Most of these differences were at the edges of patches and within the "lost forest", as seen in Figure 7. 
The differences between the two results were quantified and analyzed. Then, they were separated into two groups - changes detected only using RapidEye (31 ha, or $8 \%$ of all losses) and changes detected only using aerial images (12 ha, or $3 \%$ of all losses) (Table 5 ).

Table 5. Calculated forest losses by data and method utilized.

\begin{tabular}{ccc}
\hline Data Source & $\begin{array}{c}\text { Total Area Detected } \\
\text { in Hectares }\end{array}$ & $\begin{array}{c}\text { Area Detected Only by a Specific } \\
\text { Dataset in Hectares and (\% of Total } \\
\text { Area Detected Using This Method) }\end{array}$ \\
\hline RapidEye & 392 & $31(8 \%)$ \\
Aerial images & 373 & $12(3 \%)$ \\
RapidEye and Aerial images & 361 & \\
\hline
\end{tabular}

Visual comparison of the changes detected solely by RapidEye data with the reference data shows clearly that these were actual changes in forest cover caused by either forest harvest or trees being thrown by the storm (Figure 8). However, an examination of the changes detected only by the aerial image analysis showed that some of these changes were not detectable using the RapidEye data, as will be discussed later.

Figure 8. Two examples showing objects classified as "lost forest" overlaid on a RapidEye image from 19 April (left), a RapidEye image from 22 August (middle), and aerial images from 22 August (right). In example A, forest cover losses that were detected solely by RapidEye images are shown. In example B, the aerial image on the right clearly shows the windthrown trees detected solely by the analysis using RapidEye data.
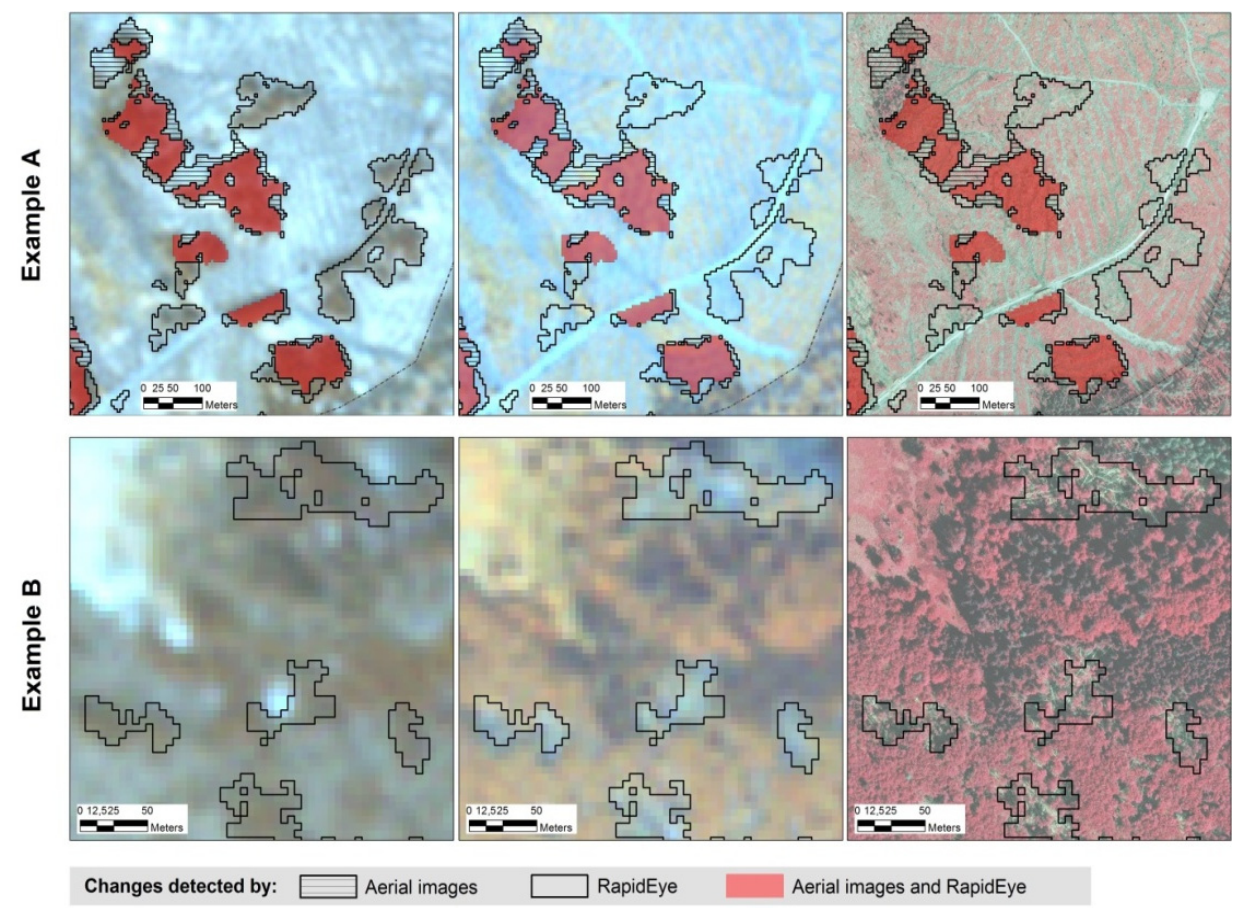

The costs of using RE and those associated with AI were estimated. The results of this comparison, presented in Table 6, show that implementing the RE methodology cost $€ 5,660$, while the visual 
interpretation of the AI would have cost an estimated $€ 22,200$. This indicates that visual interpretation of AI would cost about four times as much as the method using RE data.

Table 6. Cost comparison of change analysis using RapidEye data and aerial images.

\begin{tabular}{ccc}
\hline Category & RapidEye (Euros) & Aerial Images (Euros) \\
\hline Raw data & $(8$ images $\times € 593)=4750$ & $(1000$ images $\times € 18)=18,000$ \\
Preprocessing & $(10 \mathrm{WH} \times € 35)=350$ & $(40 \mathrm{WH} \times € 35)=1400$ \\
Data analysis & $(16 \mathrm{WH} \times € 35)=560$ & $(80 \mathrm{WH} \times € 35)=2800$ \\
Total & 5660 & 22,200 \\
\hline
\end{tabular}

\section{Discussion}

Implementing this methodology using RapidEye data to detect changes in forest cover produced accurate results, and even small changes in forest cover were detected. The results were comparable to those produced using the official aerial images mapping provided by BFNP. The availability of multi-seasonal RapidEye data enabled the detection of forest losses over two periods of time within one year. This allowed for a better definition of the factors that caused the changes in forest cover. As an illustration, during the first period alone, from April to June/July, a substantial area of about 157 ha of forest cover was lost. This change was due solely to management undertaken as protection against the bark beetle, which indicates the aggressiveness of the calamity. In contrast to RE data, aerial images are only collected once a year in the special case of the BFNP and triennially in the rest of Bavaria. This means, it is not feasible to acquire such timely information from aerial images given the current image update frequency. Additionally, a predefined acquisition date is not possible for the aerial image survey. In the BFNP, the survey typically takes place at the end of the vegetation period. Another advantage, of using the multi-seasonal data, was its helpfulness in overcoming the problem of clouds. In contrast, using less frequently acquired optical data is usually a challenge due to cloud and haze presence [6,17].

The hybrid technique developed here employed multi-seasonal RapidEye data and provided rapid mapping of forest cover losses with up to $96 \%$ accuracy. Comparable results, depending on the resolution of the sensor, have been reported in the literature when object-based methods have been used for forest cover change detection using image datasets from sensors of high spatial resolutions. For example, Desclée et al. [16] implemented OBCD with SPOT data for forest change detection and achieved an overall accuracy of $93 \%$ and a kappa of 0.84 . In addition, Duveiller et al. [17] estimated the deforestation in central Africa using Landsat data and OBCD with an overall accuracy of 91\%. McDermid et al. [19] also used Landsat and OBCD in forest change detection and achieved an overall accuracy of $84 \%$ and a kappa of 0.69 . Moreover, some studies which have utilized a hybrid method similar to that used here have achieved comparable results. In Canada, McDermid et al. [20] applied the hybrid method to Landsat data and reported an overall accuracy of 93\% and a kappa of 0.889 . Another study applied this method using a combination of SPOT data and aerial images and reported an overall accuracy of 94\% [15]. However, none of these studies focused on sudden changes; but instead detected inter-annual changes over periods of three to 35 years. Additionally, they did not deal with the problem of cloud presence, but rather, recommended either using more frequently acquired optical data or active system observation. 
As an alternative solution using data from satellite sources to map the same storm event addressed here, Rappl et al. [10] and Thiele et al. [11] demonstrated the use of data from the active satellite system, TerraSAR-X, to overcome the problem of clouds. This also allowed for rapid mapping of the remaining forest cover after the storm, and made comparison to pre-event forest cover estimates derived from RapidEye data or aerial images feasible. Although their results offered rapid estimation of the destruction, it was not possible to compare their results to ours, as there was no accuracy assessment conducted. In addition, the relatively small area of coverage and high cost of the TerraSAR-X data and aerial images remain an issue in using them more frequently, such as for operational use.

Technically, juxtaposing the performance of the RapidEye change detection performed here against that of the aerial images, some differences were detected. Some of these differences were due to the influence of the user in aerial image interpretation, who will naturally try, during manual digitization, to delineate objects that have smooth borders rather than zigzag ones. Moreover, in the manual digitization procedure, many small patches, which do not represent actual forest cover losses, were included in the "lost forest" class. The implications of manual delineation were discussed by Heurich et al. [4], and Kautz et al. [5], and can be explained by the minimum size of the unit of interest, which is a group of trees or even a stand, rather than a single tree. Our analysis of the differences between the AI interpretation and the RapidEye analysis showed that the RapidEye approach was able to detect solely many of the changes that occurred-about $8 \%$ of all losses. However, few objects of those $8 \%$ were mistakenly identified as losses, this was due to differences in phenology between April and June/July, and those objects were located mainly in deciduous stands. This can be explained by the increase in the spectral reflectance in the red edge bands in this period due to the change from leaf-off to leaf-on. Only 3\% of all losses were not detected by RapidEye, and these were mainly due to the very small extent of these changes, such as only a few single trees, which had fallen within a healthy stand. Therefore, they were too fine to be detected using spectral information alone without actual visual interpretation of AI. Another reason these changes were not found is that they were located among the deciduous stands and shaded areas of the surrounding remaining trees; therefore they were difficult to detect using spectral properties alone. Also, it might be that a few of the changes detected in the AI interpretation occurred before April, 2011, and therefore, were not detectable in the RapidEye change analysis. However, some of these changes were still easily detectable at the center of the damages but not at the periphery. This was due to the complex structure at the periphery, which included thrown trees and healthy standing ones. Similar results were found using Landsat data and the hybrid method in Brazil [18], in which there were also a few objects which were mistakenly identified as losses, when in fact, no actual loss had occurred. The majority of these mistakenly identified losses were due to shaded areas among the tree crowns, especially in less dense forest stands.

From an operational point of view, the hybrid method implemented here allows flexibility and adaptability to a subsequent data set. This ensures continuous monitoring supported by the high temporal resolution of RapidEye data. Although the analysis of the RE data achieved fast and cost effective results, $3 \%$ of the changes detected in the official AI survey were not detected using the RE analysis. On the other hand, the RE data and analysis cost only $25 \%$ of that of the aerial image analysis. Even though, RE results cannot be expected to fully achieve the results possible using aerial images, 
they can provide additional support for subjective and time-consuming visual interpretation of aerial images.

\section{Conclusions}

This study investigated the feasibility of updating forest cover databases in cases of both regular management activities and sudden events that cause changes in forest cover, such as bark beetle attacks and storm events, by means of RE satellite data. Overall, the five-meter spatial resolution of RapidEye data was suitable for performing detection of forest cover changes. Use of the RE data achieved rapid and cost-effective results that were comparable to those obtained from aerial image interpretation. The high temporal resolution of the RapidEye constellation was useful for the regular forest cover updates on a seasonal basis. This shows the potential of the new high temporal resolution satellites (e.g., Landsat 8 and Sentinels) for use in forest database updates. Hence, sudden changes may be detected in very short period, and addressed efficiently using appropriate management techniques. Local authorities and stakeholders may benefit from the outcomes of this study. The information generated is invaluable to decision makers in planning initial clean-up operations following forest disturbances due to storm events and biotic calamities, as well as in updating existing forest databases.

Although the work described here was restricted to forests in the BFNP, the motivation for the study arose from the EUS-FH project goal [7]. The study found that RE mapped $97 \%$ of the changes detected using AI interpretation at only $25 \%$ of the cost of AI interpretation. In addition, the annual AI survey is available only for the BFNP, while surveys are done only once every three years for the rest of Bavarian state. Moreover, multi-seasonal RE data (acquired every 45 days) are available for all of Germany. Thus, we conclude that the generalization of the methodology presented here to the project's other test areas distributed throughout Bavaria appears to be a must.

\section{Acknowledgments}

The research work presented here was funded by the Federal Ministry of Economics and Technology under number 50EE0919 within the program "synergistic use of RapidEye and TerraSAR-X data for applications" of the Space Agency of the German Aerospace Centre (DLR). The work was also supported by the German Research Foundation (DFG) and the Technische Universität München within the funding program Open Access Publishing. Thanks go to RESA of the DLR, under project number 317, for the provision of RapidEye data and especially for the excellent support they provided us in this research. Thanks also go to the Bavarian Forest Administration and BFNP Administration for providing the official geo-data and the digital aerial images used in this analysis, and to Laura Carlson for language editing of the manuscript.

\section{Author Contributions}

The paper was written by Alata Elatawneh with a contribution by Ioannis Manakos. Additional data collection and preparation was done by Adelheid Wallner. The research approach was developed by Alata Elatawneh and Thomas Schneider. The research coordination and significant contribution to the discussion was done by Thomas Knoke. 


\section{Conflicts of Interest}

The authors declare no conflict of interest.

\section{References}

1. Fischer, A.; Lindner, M.; Abs, C.; Lasch, P. Vegetation dynamics in central European forest ecosystems (near-natural as well as managed) after storm events. Folia Geobot 2002, 37, 17-32.

2. Wermelinger, B. Ecology and management of the spruce bark beetle Ips typographus-A review of recent research. For. Ecol. Manag. 2004, 202, 67-82.

3. Eriksson, M.; Pouttu, A.; Roininen, H. The influence of windthrow area and timber characteristics on colonization of wind-felled spruces by Ips typographus (L.). For. Ecol. Manag. 2005, 216, $105-116$.

4. Heurich, M.; Ochs, T.; Andresen, T.; Schneider, T. Object-orientated image analysis for the semi-automatic detection of dead trees following a spruce bark beetle (Ips typographus) outbreak. Eur. J. For. Res. 2010, 129, 313-324.

5. Kautz, M.; Dworschak, K.; Gruppe, A.; Schopf, R. Quantifying spatio-temporal dispersion of bark beetle infestations in epidemic and non-epidemic conditions. For. Ecol. Manag. 2011, 262, 598-608.

6. Nagendra, H.; Lucas, R.; Honrado, J.P.; Jongman, R.H.G.; Tarantino, C.; Adamo, M.; Mairota, P. Remote sensing for conservation monitoring: Assessing protected areas, habitat extent, habitat condition, species diversity, and threats. Biodivers. Monit. 2013, 33, 45-59.

7. Schneider, T.; Elatawneh, A.; Rahlf, J.; Kindu, M.; Rappl, A.; Thiele, A.; Boldt, M.; Hinz, S. Parameter Determination by RapidEye and TerraSAR-X Data: A Step Toward a Remote Sensing Based Inventory, Monitoring and Fast Reaction System on Forest Enterprise Level. In Lecture Notes in Geoinformation and Cartography; Krisp, J.M., Meng, L., Pail, R., Stilla, U., Eds.; Springer Berlin Heidelberg: Berlin, Heidelberg, Germany, 2013; pp. 81-107.

8. De Kok, R.; Schneider, T.; Baatz, M.; Ammer, U. Object Based Image Analysis of High Resolution Data in the Alpine Forest Area. Presented at Joint Workshop for ISPRS WG I/1, I/3 AND IV/4, Sensors and Mappinhg from Space, Hanover, Germany, 27 September 1999; pp. 27-30.

9. RapidEye, AG. Satellite Imagery Product Specifications, 2012. Available online: http://www. rapideye.com/upload/RE_Product_Specifications_ENG.pdf (accessed on 13 March 2013).

10. Rappl, A.; Elatawneh, A.; Thiele, A.; Troycke, A.; Schneider, T.; Knoke, T.; Hinz, S. Einsatz der Fernerkundungssysteme TerraSAR-X und RapidEye im Katastrophenmanagement von Windwurfereignissen. In Informationstechnologie für eine nachhaltige Landbewirtschaftung, Fokus Forstwirtschaft, Referate der 32. GIL-Jahrestagung, Freising, Germany, 29 February-1 March 2012; Clasen, M., Ed.; Ges. für Informatik: Bonn, Germany, 2012; Volume 194, pp. 235-238.

11. Thiele, A.; Boldt, M.; Hinz, S. Automated Detection of Storm Damage in Forest Areas by Analyzing TerraSAR-X Data. In Proceedings of the 2012 IEEE International Geoscience and Remote Sensing Symposium (IGARSS), Munich, Germany, 22-27 July 2012; pp. 1672-1675. 
12. Brunner: Sturmwürfe im Nationalpark Rasch Aufarbeiten 2012. Available online: http://www. forstpraxis.de/brunner-sturmwuerfe-nationalpark-rasch-aufarbeiten (accessed on 3 February 2012).

13. Hussain, M.; Chen, D.; Cheng, A.; Wei, H.; Stanley, D. Change detection from remotely sensed images: From pixel-based to object-based approaches. ISPRS J. Photogramm. Remote Sens. 2013, 80, 91-106.

14. Chen, G.; Hay, G.J.; Carvalho, L.M.T.; Wulder, M.A. Object-based change detection. Int. J. Remote Sens. 2012, 33, 4434-4457.

15. Willhauck, G.; Schneider, T.; De Kok, R.; Ammer, S. Comparison of Object Oriented Classification Techniques and Standard Image Analysis for the Use of Change Detection between SPOT Multispectral Satellite Images and Aerial Photos. In Proceedings of the XIX ISPRS Congress, Amsterdam, The Netherlands, 16-23 July 2000.

16. Desclée, B.; Bogaert, P.; Defourny, P. Forest change detection by statistical object-based method. Remote Sens. Environ. 2006, 102, 1-11.

17. Duveiller, G.; Defourny, P.; Desclée, B.; Mayaux, P. Deforestation in Central Africa: Estimates at regional, national and landscape levels by advanced processing of systematically-distributed Landsat extracts. Earth Obs. Terr. Biodivers. Ecosyst. Spec. Issue 2008, 112, 1969-1981.

18. Carvalho, L.M.T.; Fonseca, L.M.G.; Murtagh, F.; Clevers, J.G.P.W. Digital change detection with the aid of multiresolution wavelet analysis. Int. J. Remote Sens. 2001, 22, 3871-3876.

19. McDermid, G.J.; Pape, A.; Chubey, M.; Franklin, S. Object Oriented Analysis for Change Detection. In Proceedings of the 25th Canadian Symposium on Remote Sensing, Montréal, Canada, 14-17 October 2003.

20. McDermid, G.J.; Linke, J.; Pape, A.D.; Laskin, D.N.; McLane, A.J.; Franklin, S.E. Object-based approaches to change analysis and thematic map update: Challenges and limitations. Can. J. Remote Sens. 2008, 34, 462-466.

21. Wulder, M.A.; White, J.C.; Coops, N.C.; Butson, C.R. Multi-temporal analysis of high spatial resolution imagery for disturbance monitoring. Remote Sens. Environ. 2008, 112, 2729-2740.

22. Heurich, M.; Neufanger, M. Die Wälder des Nationalparks Bayerischer Wald: Ergebnisse der Waldinventur 2002/2003 im geschichtlichen und waldökologischen Kontext; Nationalparkverwaltung Bayerischer Wald: Grafenau, Germany, 2005.

23. Escherich, K. Die Forstinsekten Mitteleuropas ein Lehr-und Handbuch Band 2 Spezielle Teil Abt. In 1 Die Urinsekten, die Geradflügler, die Netzflügler und die Käfer. Systematik, Biologie, forstliches Verhalten und Bekämpfung; P. Parey: Berlin, Germany, 1923.

24. Heurich, M. Waldentwicklung im Bergwald nach Windwurf und Borkenkäferbefall; Nationalparkverwaltung Bayerischer Wald: Grafenau, Germany, 2001.

25. Rall, H.; Martin, K. Luftbildauswertung zur Waldentwicklung im Nationalpark Bayerischer Wald 2001; Nationalparkverwaltung Bayerischer Wald: Grafenau, Germany, 2002.

26. Walter, V. Object-based classification of remote sensing data for change detection. ISPRS J. Photogramm. Remote Sens. 2004, 58, 225-238.

27. Singh, A. Review article digital change detection techniques using remotely-sensed data. Int. J. Remote Sens. 1989, 10, 989-1003. 
28. Elatawneh, A.; Rappl, A.; Schneider, T.; knoke, T. A semi-automated method of forest cover losses detection using RapidEye images: A case study in the Bavarian forest National Park. Presented at Vom Algorithmus zum Produkt: Tagungsband zum 4. RESA-Workshop, Neustrelitz, Germany, 21-22 March 2012; Borg, E., Ed.; GITO, Verl. für Industrielle Informationstechnik und Organisation: Berlin, Germany, 2012; pp. 183-200.

29. Huang, C.; Song, K.; Kim, S.; Townshend, J.R.G.; Davis, P.; Masek, J.G.; Goward, S.N. Use of a dark object concept and support vector machines to automate forest cover change analysis. Remote Sens. Environ. 2008, 112, 970-985.

30. Biging, G.; Colby, D.; Congalton, R. Sampling Systems for Change Detection Accuracy Assessment. In Remote Sensing Change Detection: Environmental Monitoring Methods and Applications; Lunetta, R.S.E.C., Ed.; Ann Arbor Press: Chelsea, UK, 1998.

31. Congalton, R.G.; Green, K. Assessing the Accuracy of Remotely Sensed Data: Principles and Practices; CRC/Lewis Publications: Boca Raton, FL, USA, 1999.

32. Foody, G.M. Status of land cover classification accuracy assessment. Remote Sens. Environ. 2002, 80, 185-201.

(C) 2014 by the authors; licensee MDPI, Basel, Switzerland. This article is an open access article distributed under the terms and conditions of the Creative Commons Attribution license (http://creativecommons.org/licenses/by/3.0/). 